Mona Kamal ElDeeb ${ }^{1}$, Gihane Ibrahim Khalil ${ }^{1}$, Moataz Ahmed Zaki², El-Sayed Mehana ${ }^{3}$, Sahar Omer ${ }^{1}$

${ }^{1}$ Department of Chemical Pathology, Medical Research Institute, Alexandria University, Alexandria, Egypt

2Department of Experimental and Clinical Internal Medicine (Cardiology), Medical Research Institute, Alexandria University, Alexandria, Egypt

${ }^{3}$ Department of Radiodiagnosis Medical Research Institute, Alexandria University, Alexandria, Egypt

\title{
Role of serum allograft inflammatory factor-1 (AIF-1) in Egyptian type 2 diabetic patients
}

\section{ABSTRACT}

Background. Diabetes mellitus (DM) is a powerful and independent risk factor for cardiovascular disease. The atherosclerosis process in diabetes is indistinguishable from that of the nondiabetic population, but it begins earlier and is often more extensive and more severe. AIF-1 promotes chemotaxis, spreading and migration of macrophages and vascular smooth muscle cells (VSMCs) which suggest a role of AIF-1 in the atherosclerotic plaque formation. Thus, this study determines the role of AIF-1 in the Egyptian type 2 diabetic patients.

Results. The level of AIF-1 was significantly higher in the type 2 diabetic group when compared to the control group ( $p=0.000$ ). In type 2 diabetic patients group, there was a significant positive correlation between CIMT and AIF-1 ( $r=0.468, p=0.000)$. In addition to the positive correlation between CIMT and AIF-1, CIMT in regression model analysis was significantly positive contributing to the outcome variable (AIF-1) $(p<0.05)$, denoting the possible role of elevated serum AIF-1 level in atherosclerotic process with further studies on larger scale needed. (Clin Diabetol 2019; 8, 6: 271-276)

Key words: allograft inflammatory factor-1 (AIF-1), diabetes mellitus (DM), atherosclerosis, inflammation

Address for correspondence:

Mona Kamal ElDeeb

Department of Chemical Pathology, Medical Research Institute

Alexandria University, Alexandria, Egypt

Phone: (+203) 4285455, 4282373, 4288233

Fax: (+203) 4283719

e-mail: mona.eldeeb@alexu.edu.eg

Clinical Diabetology 2019, 8, 6, 271-276

DOI: $10.5603 /$ DK.2019.0025

Received: 07.07.2019

Accepted: 26.09.2019

\section{Introduction}

Diabetes mellitus (DM) is a powerful and independent risk factor for cardiovascular disease which remains to be the major cause of death in type 2 diabetic patients [1, 2]. Low grade inflammation and activation of the immune system play a role in the common pathogenesis of both insulin resistance and endothelial dysfunction and subsequently the development of type 2 diabetes and atherosclerosis [2-4].

Subclinical vascular disease in type 2 diabetic patients was proved to be assessed by carotid intima media thickness (CIMT) [5-7] and the presence of plaques (calcified or not) [8] specially in patients with normal renal function by many researches. The dyslipidemic lipid profile (increased LDL and total cholesterol) usually associated with type 2 diabetes and adds more impact to the process of atherosclerosis process development in these patients [9-11].

AIF-1 (ionized calcium-binding adaptor molecule-1 (Iba1) is a $17 \mathrm{kDa}$ conserved structural cytoplasmic, calcium-binding, inflammation-responsive scaffold protein $[12,13]$. It is one of the EF hand proteins' family $[14,15]$.

AIF-1 was originally identified in rat cardiac allografts with chronic rejection. In humans, AIF-1 is involved in many pathological processes where it has been found to be expressed by activated T cells, vascular endothelial cells and blood vessel smooth muscle cells after a balloon injury ie: vascular trauma inducible cytokine $[16,17]$. Thus AIF-1 may play a role in endothelial dysfunction, macrophages and VSMCs activation, migration, reorganization and tissue remodelling as a response to endothelial damage $[3,16,18]$.

The in vivo expression of AIF-1 in human VSMCs in atherosclerotic plaques supported the in vitro studies 
that have shown the role of AIF-1 in atherosclerotic plaque formation through promotion of chemotaxis, cell attachment, spreading and migration of macrophages and VSMCs [19].

This work aimed was to study serum AIF-1 in type 2 diabetic patients.

\section{Materials and methods}

One hundred subjects were included in the study after approval of the ethical committee of Medical Research Institute and informed consents was taken. The included subjects were divided into two groups; Forty apparently healthy volunteers as a control group (group 1), sixty type 2 diabetic patients (group 2). Subjects with obesity, urinary tract infections UTI and renal impairment or increased urinary proteins were excluded. The source of finance was supplied by authors.

To all studied subjects; thorough history taking was done including history of cardiovascular diseases, smoking habits, drinking habits, medications such as anti-diabetic, anti-hypertensive and anti-hyperlipemic drugs. Complete physical examination with special stress on BMI calculation, cardiovascular examination and measuring the carotid intima media thickness (CIMT) and presence of plaques (calcified or not) using a $\beta$ mode ultrasound.

The following laboratory investigations were done to all participating subjects: quantitation of urinary albumin, urinary proteins, creatinine, calculation of urinary albumin and protein to creatinine ratio, estimation of serum fasting and postprandial glucose, urea, creatinine, calculation of estimated glomerular filtration rate (eGFR) [20], urine cultures and determination of hemoglobin $A_{1 c}$ [21]. In addition to estimation of serum lipid profile (total cholesterol (TC), high density lipoprotein cholesterol (HDL-C), triglycerides with calculation of low density lipoprotein cholesterol (LDL-C). Also, serum C-reactive protein (CRP) [22] was estimated and serum AIF-1 by ELISA technique (Biocompare, South San Francisco, USA, catalog no. SEC288Hu) [23].

Data analysis was performed by using SPSS for Windows, version 20 (Statistical Package of social sciences, Chicago, USA) [24]. Normality of the quantitative variables was determined with the use of the Kolmogrov-Smirnov test. Where normally distributed data were presented as mean \pm standard deviation and unpaired Student's t-test was used to compare a variable across two subgroups in addition to Pearson's correlation test was used to investigate the relationship between different quantitative variables. The non-normal distributed data were presented as median (minimum-maximum). Non parametric Mann-Whitney test was used to compare the variables across two groups. Stepwise multiple
Table 1. Statistical significance of clinical data of the studied groups

\begin{tabular}{|c|c|c|}
\hline Item & $\begin{array}{l}\text { Group } 1 \\
(n=40)\end{array}$ & $\begin{array}{l}\text { Group } 2 \\
(n=60)\end{array}$ \\
\hline \multicolumn{3}{|c|}{ Age (years) } \\
\hline Mean & 46.15 & 56.87 \\
\hline SD & \pm 8.41 & \pm 8.00 \\
\hline $\mathrm{p}$ & \multicolumn{2}{|c|}{$0.000 * *$} \\
\hline \multicolumn{3}{|l|}{ Sex } \\
\hline Males & $19(47.50 \%)$ & $25(41.79 \%)$ \\
\hline Females & $21(52.50 \%)$ & $35(58.30 \%)$ \\
\hline $\mathrm{p}$ & \multicolumn{2}{|c|}{0,794} \\
\hline \multicolumn{3}{|c|}{ Weight [kg] } \\
\hline Mean & 68.15 & 74.62 \\
\hline SD & \pm 4.38 & \pm 5.45 \\
\hline $\mathrm{p}$ & \multicolumn{2}{|c|}{$0.000 * *$} \\
\hline \multicolumn{3}{|c|}{ Height [m] } \\
\hline Mean & 1.71 & 1.75 \\
\hline SD & \pm 0.05 & \pm 0.04 \\
\hline $\mathrm{p}$ & \multicolumn{2}{|c|}{$0.001 *$} \\
\hline \multicolumn{3}{|c|}{ BMI $\left[\mathrm{kg} / \mathrm{m}^{2}\right]$} \\
\hline Mean & 23.36 & 24.38 \\
\hline SD & \pm 1.39 & \pm 0.75 \\
\hline $\mathrm{p}$ & \multicolumn{2}{|c|}{$0.000 * *$} \\
\hline \multicolumn{3}{|c|}{ Hypertension } \\
\hline Yes & $0(0 \%)$ & $19(31.7 \%)$ \\
\hline No & $20(100 \%)$ & $41(68.3)$ \\
\hline $\mathrm{p}$ & \multicolumn{2}{|c|}{$0.004^{*}$} \\
\hline \multicolumn{3}{|c|}{ CIMT [mm] } \\
\hline Mean & 0.285 & 1.235 \\
\hline SD & \pm 0.12 & \pm 0.32 \\
\hline $\mathrm{p}$ & \multicolumn{2}{|c|}{$0.000^{* *}$} \\
\hline \multicolumn{3}{|c|}{ Plaques and calcification } \\
\hline Yes & $0(0 \%)$ & $15(25 \%)$ \\
\hline No & $20(100 \%)$ & 45 (75\%) \\
\hline$p$ & \multicolumn{2}{|c|}{$0.013^{*}$} \\
\hline
\end{tabular}

$\chi^{2}$, Chi square test, Mann-Whitney test; $p-p$ value for comparing between the two groups; *statistically significant at $p \leq 0.05$

regression analysis was conducted to test the variables contributing in the AIF-1 marker.

\section{Results}

Blood pressure, CIMT and presence of plaques and calcification in type 2 diabetic patients was significantly increased comparing to controls $(p=0.004, p=0.000$, $\mathrm{p}=0.013$ ) respectively (Table 1 ).

Glycemic control measures showed significant increase in fasting, post prandial blood glucose and $\mathrm{HbA}_{1 \mathrm{c}}$ in type 2 diabetic patients than controls ( $p=$ $0.000, p=0.000, p=0.000$ ) respectively (Table 2 ). 
Table 2. Statistical significance of laboratory data in the studied groups

\begin{tabular}{|c|c|c|}
\hline Item & $\begin{array}{l}\text { Group } 1 \\
(n=40)\end{array}$ & $\begin{array}{l}\text { Group } 2 \\
(n=60)\end{array}$ \\
\hline \multicolumn{3}{|c|}{ Total cholesterol [mg/dL] } \\
\hline Mean & 152.85 & 189.25 \\
\hline SD & \pm 11.27 & \pm 51.53 \\
\hline $\mathrm{p}$ & \multicolumn{2}{|c|}{$0.003^{*}$} \\
\hline \multicolumn{3}{|c|}{$\mathrm{HDL}-\mathrm{C}[\mathrm{mg} / \mathrm{dL}]$} \\
\hline Mean & 51.05 & 37.55 \\
\hline SD & \pm 6.70 & \pm 9.71 \\
\hline $\mathrm{p}$ & \multicolumn{2}{|c|}{$0.000^{* *}$} \\
\hline \multicolumn{3}{|l|}{$\mathrm{TG}[\mathrm{mg} / \mathrm{dL}]$} \\
\hline Mean & 80.05 & 128.8 \\
\hline SD & \pm 25.81 & \pm 47.29 \\
\hline $\mathrm{p}$ & \multicolumn{2}{|c|}{$0.000^{* *}$} \\
\hline \multicolumn{3}{|c|}{ LDL-C [mg/dL] } \\
\hline Mean & 85.79 & 125.94 \\
\hline SD & \pm 10.38 & \pm 43.83 \\
\hline $\mathrm{p}$ & \multicolumn{2}{|c|}{$0.000^{* *}$} \\
\hline \multicolumn{3}{|l|}{ CRP [mg/L] } \\
\hline Median & 3.00 & 10.00 \\
\hline Min-Max & $(2.00-4.50)$ & $(2.00-650.00)$ \\
\hline $\mathrm{p}$ & \multicolumn{2}{|c|}{$0.000^{* *}$} \\
\hline \multicolumn{3}{|c|}{ Fasting serum glucose $[\mathrm{mg} / \mathrm{dL}]$} \\
\hline Mean & 87.35 & 203.53 \\
\hline SD & \pm 9.4 & \pm 72.13 \\
\hline $\mathrm{p}$ & \multicolumn{2}{|c|}{$0.000 * *$} \\
\hline \multicolumn{3}{|c|}{ Postprandial serum glucose $[\mathrm{mg} / \mathrm{dL}]$} \\
\hline Mean & 108.15 & 190.025 \\
\hline SD & \pm 15.39 & \pm 76.33 \\
\hline $\mathrm{p}$ & \multicolumn{2}{|c|}{$0.000^{* *}$} \\
\hline \multicolumn{3}{|l|}{$\mathrm{HbA}_{1 \mathrm{c}}(\%)$} \\
\hline Mean & 4.63 & 7.93 \\
\hline SD & \pm 0.37 & \pm 2.49 \\
\hline $\mathrm{p}$ & \multicolumn{2}{|c|}{$0.000^{* *}$} \\
\hline \multicolumn{3}{|c|}{ Serum urea $[\mathrm{mg} / \mathrm{dL}]$} \\
\hline Mean & 27.6 & 29.47 \\
\hline SD & \pm 6.83 & \pm 7.32 \\
\hline $\mathrm{p}$ & \multicolumn{2}{|c|}{0.336} \\
\hline \multicolumn{3}{|c|}{ Serum creatinine $[\mathrm{mg} / \mathrm{dL}]$} \\
\hline Mean & 0.78 & 0.78 \\
\hline SD & \pm 0.14 & \pm 0.11 \\
\hline $\mathrm{p}$ & 0.957 & \\
\hline eGFR $[\mathrm{ml} / \mathrm{mi}$ & & \\
\hline Median & 103.5 & 98.6 \\
\hline Min-Max & $(91.70-134.7)$ & $(90.10-157.60$ \\
\hline $\mathrm{p}$ & 0. & \\
\hline Urine protei & {$[\mathrm{mg} / \mathrm{g}]$} & \\
\hline Mean & 100.5 & 110.93 \\
\hline SD & \pm 23.74 & \pm 25.17 \\
\hline $\mathrm{p}$ & 0. & \\
\hline Urine album & io $[\mathrm{mg} / \mathrm{g}]$ & \\
\hline Mean & 20.25 & 22.67 \\
\hline SD & \pm 4.13 & \pm 4.6 \\
\hline $\mathrm{p}$ & 0. & \\
\hline Serum AlF1 & & \\
\hline Median & 90.00 & 1.235 \\
\hline Min-Max & $(20.00-500.00)$ & \pm 0.32 \\
\hline $\mathrm{p}$ & 0.0 & $0^{* *}$ \\
\hline
\end{tabular}

$\chi^{2}$, Chi square test, Mann-Whitney test; $p-p$ value for comparing between the two groups; *statistically significant at $p \leq 0.05$

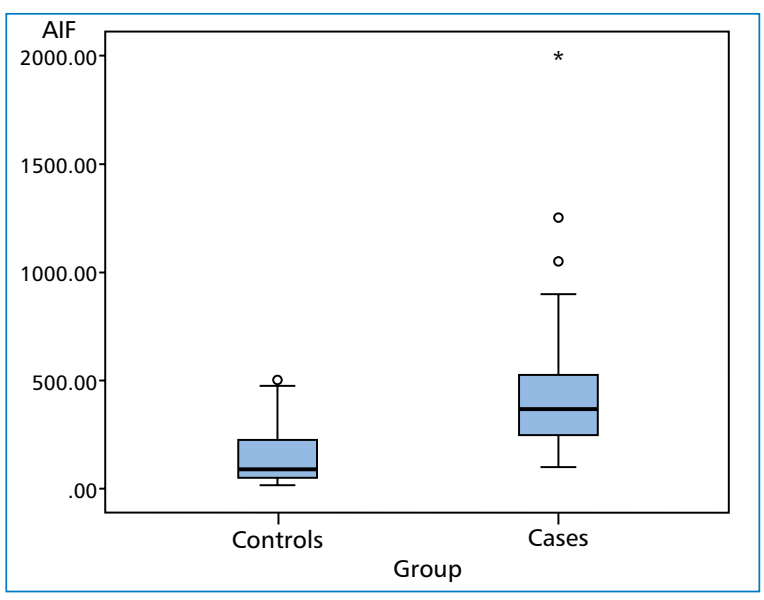

Figure 1. Box plot illustrates the median and range of serum AlF-1 readings $[\mathrm{pg} / \mathrm{mL}]$ among the studied groups. Box plot represents the interquartile range $25^{\text {th }}-75^{\text {th }}$ percentile. The wiskers below and above represents $10-90$ percentile. The line across each box represents the median value. Significant increase in AIF-1 in the group of diabetic atherosclerotic patients when compared to the control group $(p=0.000)$

Table 3. Statistical significant correlations between the studied parameters in the type2 diabetic group (group 2)

\begin{tabular}{lcc}
\hline Item & $\begin{array}{c}\text { Correlation } \\
\text { coefficient }(r)\end{array}$ & $\begin{array}{c}\text { Significance } \\
(p \text {-value })\end{array}$ \\
\hline AlF-1 and creatinine & 0.338 & 0.008 \\
AlF-1 and CIMT & 0.468 & 0.000 \\
$\mathrm{BMI}$ and $\mathrm{HbA}_{1 \mathrm{c}}$ & 0.343 & 0.007 \\
$\mathrm{BMI}$ and fasting serum & 0.376 & 0.003 \\
glucose & & \\
$\mathrm{HbA}_{1 \mathrm{c}}$ and CIMT & 0.257 & 0.047 \\
\hline
\end{tabular}

Lipid profile and CRP levels showed significant increase in cholesterol, triglycerides, LDL and CRP in type 2 diabetic patients than control $(p=0.003$, $p=0.000, p=0.000, p=0.000$ ) respectively (Table 2).

Renal functions tests showed only a significant increase in albumin creatinine ratio in the type 2 diabetic patients than controls ( $p=0.04$ ) (Table 2).

AlF-1 showed significant increase in type 2 diabetic patients than control group $(p=0.000)$ (Table 2 , Figure 1).

Pearson's correlation test showed positive significant correlations only between AIF- 1 and creatinine level in addition to CIMT ( $r=0.3380, r=0.468)$ ( $p=0.008, p=0.000$ ) respectively in type 2 diabetic patients (Table 3 ).

Multiple regression analysis showed the overall model was statistically significant $(F=3.309$, 
$p=0.001)$. Where, CIMT was significantly positive contributing to the outcome variable (AIF-1) $(p<0.05)$, while other predictors were not significantly contributing to the outcome $(p>0.05)$ (Table 4).

\section{Discussion}

Diabetes when accompanied by other major cardiovascular risk factors, such as hypertension, dyslipidemia, and smoking, show marked increase in the incidence of atherosclerosis. The atherosclerosis process begins earlier and more aggressive in diabetes and indistinguishable from nondiabetic population [2]. The atherogenic lipid profile characterized by elevated triglycerides and low levels of high-density lipoprotein (HDL) cholesterol are major modifiable risk factors contributing to progressive cardiovascular risk generally in addition to both type 2 diabetes and metabolic syndrome $[25,26]$.

Atherosclerosis is known to be an inflammatory disease as an overall process where inflammatory cells (pro-inflammatory cytokines secreting cells) such as neutrophils, lymphocytes and monocytes participate in the overall process of atheroscelerosis [27].

AIF-1 plays a role in endothelial cell, macrophage, T-lymphocyte, and VSMC activation, proliferation and migration which are known to play a role in inflammation $[3,16,18]$.

It has been shown that serum AIF-1 was increased in patients with diabetic nephropathy [23], also it is considered as a human adipokine produced mainly by macrophages within the white adipose tissue in obese patients and might participate in the regulation of adi- pose tissue inflammation and, in turn, insulin resistance [28]. In the present study, all the studied groups were of normal e GFR and BMI.

The level of AIF-1 was significantly higher in type 2 diabetic groups when compared to the control group $(p=0.000)$ (Figure 1). The statistical correlation in our study revealed that there was a significant positive correlation between CIMT and AIF-1 $(r=0.468, p=0.000)$ in type 2 diabetic patients group, denoting the possible role of elevated serum AIF-1 level in atherosclerotic process. In addition the significant increase in the presence of plaques and calcification in the patients than controls $(p=0.013)$ has been seen. Although there is significant increase in dyslipidemic profile of type 2 diabetic patients than controls (cholesterol, triglycerides and LDL ( $p=0.003, p=0.000, p=0.000$ ) which add to the process of atherosclerosis development in these patients, there were no significant correlations between dyslipidemia and AIF-1 level in these patients thus a study on larger scale of type 2 diabetic patients is needed.

In multiple linear regression analysis, the overall model is statistically significant $(F=3.309, p=0.001)$ and it is found that increased CIMT is significantly contributing to elevated serum AIF-1 level in type 2 diabetic patients $(p<0.05)$. Thus, elevated serum AIF-1 level in type 2 diabetic patients in addition to its positive significant correlation with CIMT add to the possible role of AIF1 in contribution to the process of atherosclerotic changes in type 2 diabetic patients. This was consistent with Berglund et al., 2012 [29] who stated that expression of AlF-1 mRNA in human carotid plaques

Table 4. Multiple regression analysis

\begin{tabular}{|c|c|c|c|c|c|c|}
\hline \multirow[t]{2}{*}{ Model } & \multicolumn{2}{|c|}{$\begin{array}{l}\text { Regression } \\
\text { coefficients }\end{array}$} & \multirow[t]{2}{*}{$\mathbf{t}$} & \multirow[t]{2}{*}{ Sig. } & \multicolumn{2}{|c|}{$\begin{array}{l}95 \% \text { confidence } \\
\text { interval for B }\end{array}$} \\
\hline & B & S.E & & & Lower bound & Upper bound \\
\hline (Constant) & 1235.852 & 1068.189 & 1.157 & 0.251 & -895.687 & 3367.39 \\
\hline Age & -6.52 & 5.094 & -1.191 & 0.280 & -16.687 & 3.648 \\
\hline BMI & -10.074 & 40.213 & -0.251 & 0.803 & -90.318 & 70.170 \\
\hline Hypertension & -139.901 & 94.727 & -1.477 & 0.144 & -328.554 & 49.124 \\
\hline Plaques and calcification & 68.936 & 115.962 & 0.594 & 0.554 & -162.462 & 300.334 \\
\hline CIMT & 502.386 & 127.204 & 3.949 & $0.001 *$ & 248.554 & 756.217 \\
\hline Fasting blood sugar & -0.449 & 0.746 & -0.602 & 0.549 & -1.939 & 1.040 \\
\hline Post prandial blood sugar & 0.118 & 0.703 & 0.168 & 0.867 & -1.284 & 1.520 \\
\hline Albumin to creatinine ratio & 0.467 & 0.897 & 0.134 & 0.890 & -2.284 & 3.652 \\
\hline $\mathrm{HbA}_{1 \mathrm{c}}$ & -20.978 & 33.729 & -0.622 & 0.536 & -88.340 & 46.383 \\
\hline Cholesterol & 0.421 & 1.264 & 0.333 & 0.740 & -2.102 & 2.945 \\
\hline LDL & 0.169 & 1.224 & -1.581 & 0.138 & -2.273 & 2.611 \\
\hline Triglycerides & -0.185 & 1.286 & -0.144 & 0.886 & -2.753 & 2.383 \\
\hline CRP & -0.353 & 0.479 & -0.078 & 0.464 & -1.640 & 0.603 \\
\hline e-GFR & -6.404 & 3.486 & -1.837 & 0.071 & -13.361 & 0.552 \\
\hline
\end{tabular}

*Predictors are significantly contributing to the outcome variable if $p<0.05$ 


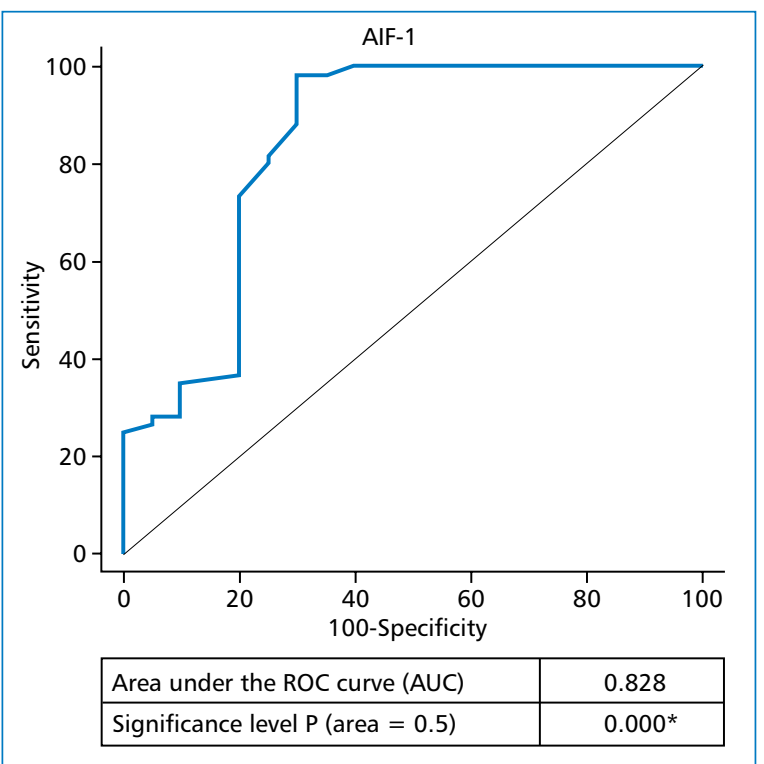

Figure 2. ROC curve for serum AIF-1 in the studied groups at a cutoff value of $120 \mathrm{pg} / \mathrm{mL}$. Receiver operating characteristic curve (ROC) for serum AlF-1 at cutoff value of $120 \mathrm{pg} / \mathrm{mL}$, the area under the ROC curve denotes the diagnostic performance of the test (0.0828), significance $p=0.000^{*}$

associates with less extracellular matrix and a more pro-inflammatory plaque and plasma profile, features that may predispose to plaque rupture.

Zhao et al, 2013 [14] reported that AlF-1 is expressed by activated lipid-rich macrophages and VSMCs during the progression of atherosclerosis. In this regard, AlF-1 may be involved in the early stage of atherosclerosis and CAD. Kelemen et al, in 2005 [30] stated that increased AlF-1 expressed in activated T lymphocytes enhance activation of adjacent arterial vascular smooth muscle cells (VSMCs) and development of atherosclerosis. Expression of AlF-1 seems to be involved in vascular smooth muscle cells and macrophages migration, chemotaxis, proliferation and tissue remodeling as a response to endothelial damage which suggest a positive role of AIF-1 in the atherosclerotic plaque formation. These in vitro studies were supported by immunohistochemical analysis which has shown in vivo protein expression of AIF-1 in human smooth muscle cells in atherosclerotic plaques [19].

In the present work, by drawing receiver operating characteristic (ROC) curve of serum AlF-1 at a cutoff value of $120 \mathrm{pg} / \mathrm{mL}$ in the studied group (Figure 2), the area under the curve (AUC) for AlF-1 was 0.843, $p \leq 0.0001$. The sensitivity, specificity, positive predictive value, negative predictive value and overall accuracy of AIF- 1 for detection of atherosclerosis were $98.33 \%$, $70 \%, 91 \%, 93 \%$ and $91 \%$ respectively. Thus, the present study supported that AIF-1 can be a helpful marker for early detection of atherosclerosis and prediction of cardiovascular complications in type 2 diabetic patients.

\section{Conclusion}

In conclusion, AlF-1 was significantly higher in the type 2 diabetic patient group (group 2) when compared to the control group (group 1). In the group of type 2 diabetic patients AIF-1 showed positive correlation with CIMT denoting the possible relation between increased AIF-1 levels and subsequent vascular damage and the process of atherosclerosis in type 2 diabetes.

Recommendations: further work is needed on a larger number of type 2 diabetic patients with higher focus on the presence of vascular calcification and atherosclerosis.

\section{Compliance with ethical standards}

All procedures followed were in accordance with the ethical standards of the responsible committee on human experimentation (institutional and national) and with the Helsinki Declaration of 1964 and later versions. Informed consent or substitute for it was obtained from all patients for being included in the study.

\section{Conflicts of interest}

EIDeeb MK, Khalil GI, Zaki MA, Mehana E, Omer S declare that they have no conflict of interest.

\section{REFERENCES}

1. Mazzone T, Chait A, Plutzky J. Cardiovascular disease risk in type 2 diabetes mellitus: insights from mechanistic studies. Lancet. 2008; 371(9626): 1800-1809, doi: 10.1016/S0140-6736(08)60768-0, indexed in Pubmed: 18502305.

2. Inzucchi SE, Sherwin RS. Diabetes mellitus. In: Cecil Medicine. Goldman L, Ausiello D (eds). 23rd Ed. Elsevier Saunders Company, Phildelphia. 2008: 1727-1759.

3. Tian $Y$, Jain S, Kelemen SE, et al. AlF-1 expression regulates endothelial cell activation, signal transduction, and vasculogenesis. Am J Physiol Cell Physiol. 2009; 296(2): C256-C266, doi: 10.1152/ ajpcell.00325.2008, indexed in Pubmed: 18787073.

4. Tian Y, Kelemen SE, Autieri MV. Inhibition of AIF-1 expression by constitutive siRNA expression reduces macrophage migration, proliferation, and signal transduction initiated by atherogenic stimuli. Am J Physiol Cell Physiol. 2006; 290(4): C1083-C1091, doi: 10.1152/ajpcell.00381.2005, indexed in Pubmed: 16291819.

5. Ninomiya H, Katakami N, Sato I, et al. Association between subclinical atherosclerosis markers and the level of accumulated advanced glycation end-products in the skin of patients with diabetes. J Atheroscler Thromb. 2018; 25(12): 1274-1284, doi: 10.5551/jat.44859, indexed in Pubmed: 29962379.

6. Rocha VZ, Santos RD. Subclinical carotid vascular disease and risk factors for atherosclerosis in type 1 and type 2 diabetes. Arch Endocrinol Metab. 2017; 61(2): 105-107, doi: 10.1590/23593997000000264 , indexed in Pubmed: 28489155.

7. Lau KK, Wong YK, Chan YH, et al. Prognostic implications of surrogate markers of atherosclerosis in low to intermediate risk patients with type 2 diabetes. Cardiovasc Diabetol. 2012; 11: 101, doi: 10.1186/1475-2840-11-101, indexed in Pubmed: 22900680. 
8. Nandalur KR, Baskurt E, Hagspiel KD, et al. Calcified carotid atherosclerotic plaque is associated less with ischemic symptoms than is noncalcified plaque on MDCT. AJR Am J Roentgenol. 2005; 184(1): 295-298, doi: 10.2214/ajr.184.1.01840295, indexed in Pubmed: 15615991.

9. Ference BA, Ginsberg HN, Graham I, et al. Low-density lipoproteins cause atherosclerotic cardiovascular disease. 1. Evidence from genetic, epidemiologic, and clinical studies. A consensus statement from the European Atherosclerosis Society Consensus Panel. Eur Heart J. 2017; 38(32): 2459-2472, doi: 10.1093/ eurheartj/ehx144, indexed in Pubmed: 28444290.

10. Linton MRF, Yancey PG, Davies SS, et al. et al.. The role of lipids and lipoproteins in atherosclerosis. 2019 Jan 3. In: Endotext Feingold KR, Anawalt B, Boyce A, et al. (eds). South Dartmouth (MA): MDText.com, Inc.; 2000.

11. Ravnskov $U$, Ravnskov $U$, Ravnskov $U$. Is atherosclerosis caused by high cholesterol? QJM. 2002; 95(6): 397-403, doi: 10.1093/ qjmed/95.6.397, indexed in Pubmed: 12037248.

12. Liu G, Ma H, Jiang $L$, et al. Allograft inflammatory factor-1 and its immune regulation. Autoimmunity. 2007; 40(2): 95-102, doi: 10.1080/08916930601083946, indexed in Pubmed: 17453710.

13. McDaniel D, Zhou X, Rigney $D$, et al. Allograft inflammatory factor-1 in cardiac ischemia re-perfusion injury: release of molecular markers in an in vitro setting. Open Journal of Organ Transplant Surgery. 2013; 03(01): 5-12, doi: 10.4236/ojots.2013.31002.

14. Zhao YY, Yan DJ, Chen ZW. Role of AIF-1 in the regulation of inflammatory activation and diverse disease processes. Cell Immunol. 2013; 284(1-2): 75-83, doi: 10.1016/j.cellimm.2013.07.008, indexed in Pubmed: 23948156.

15. Lewit-Bentley A, Réty S. EF-hand calcium-binding proteins. Curr Opin Struct Biol. 2000; 10(6): 637-643, indexed in Pubmed: 11114499.

16. Autieri MV, Carbone C, Mu A. Expression of allograft inflammatory factor-1 is a marker of activated human vascular smooth muscle cells and arterial injury. Arterioscler Thromb Vasc Biol. 2000; 20(7): 1737-1744, doi: 10.1161/01.atv.20.7.1737, indexed in Pubmed: 10894811.

17. Autieri MV. cDNA cloning of human allograft inflammatory factor-1: tissue distribution, cytokine induction, and mRNA expression in injured rat carotid arteries. Biochem Biophys Res Commun. 1996; 228(1): 29-37, doi: 10.1006/bbrc.1996.1612, indexed in Pubmed: 8912632.

18. Weber $C$, Fraemohs L, Dejana E. The role of junctional adhesion molecules in vascular inflammation. Nat Rev Immunol. 2007; 7(6): 467-477, doi: 10.1038/nri2096, indexed in Pubmed: 17525755.
19. Autieri MV, Kelemen SE, Wendt KW. AIF-1 is an actin-polymerizing and Rac1-activating protein that promotes vascular smooth muscle cell migration. Circ Res. 2003; 92(10): 1107-1114, doi: 10.1161/01.RES.0000074000.03562.CC, indexed in Pubmed: 12714565 .

20. Cockcroft DW, Gault MH. Prediction of creatinine clearance from serum creatinine. Nephron. 1976; 16(1): 31-41, doi: 10.1159/000180580, indexed in Pubmed: 1244564.

21. Sacks DB. Diabetes Mellitus. In: Tietz Textbook of Clinical Chemistry and Molecular Diagnostics. Burtis CA, Ashwood ER, Bruns DE (eds). 5th Ed. Elsevier Saunders Company, St Louis. 2012: 1441-1447.

22. Hortin GL. Amino acids, peptides, and proteins. In: Tietz Textbook of Clinical Chemistry and Molecular Diagnostics. Burtis CA, Ashwood ER, Bruns DE (eds). 5th Ed. Elsevier Saunders Company, St Louis. 2012: 538-539.

23. Fukui M, Tanaka M, Asano M, et al. Serum allograft inflammatory factor- 1 is a novel marker for diabetic nephropathy. Diabetes Res Clin Pract. 2012; 97(1): 146-150, doi: 10.1016/j. diabres.2012.04.009, indexed in Pubmed: 22560794.

24. Kirkpatrick LA, Feeney BCA. Gimple guide to IBM SPSS Statistics for Version 20. Wadsworth, Cengage Learning, Belmont, Calif. 2013.

25. Vijayaraghavan K. Treatment of dyslipidemia in patients with type 2 diabetes. Lipids Health Dis. 2010; 9: 144, doi: 10.1186/1476511X-9-144, indexed in Pubmed: 21172030.

26. Zaki NF, Sulaiman AS, Gillani WS. Clinical evaluation of Dyslipidemia among type II diabetic patients at Public hospital Penang, Malaysia. Int Arch Med. 2010; 3: 34, doi: 10.1186/1755-7682-334, indexed in Pubmed: 21092333.

27. Kastrup J. Can YKL-40 be a new inflammatory biomarker in cardiovascular disease? Immunobiology. 2012; 217(5): 483-491, doi: 10.1016/j.imbio.2011.04.007, indexed in Pubmed: 21601307.

28. Lorente-Cebrián S, Decaunes $P$, Dungner $E$, et al. Allograft inflammatory factor 1 (AIF-1) is a new human adipokine involved in adipose inflammation in obese women. BMC Endocr Disord. 2013; 13 : 54, doi: 10.1186/1472-6823-13-54, indexed in Pubmed: 24267103.

29. Berglund LM, Kotova O, Osmark $P$, et al. NFAT regulates the expression of AIF-1 and IRT-1: yin and yang splice variants of neointima formation and atherosclerosis. Cardiovasc Res. 2012; 93(3): 414-423, doi: 10.1093/cvr/cvr309, indexed in Pubmed: 22116621

30. Kelemen SE, Autieri MV. Expression of allograft inflammatory factor-1 in T lymphocytes: a role in T-lymphocyte activation and proliferative arteriopathies. Am J Pathol. 2005; 167(2): 619-626, doi: 10.1016/S0002-9440(10)63003-9, indexed in Pubmed: 16049345. 